\title{
Weathering the Storm: A Social Marketing Perspective on Disaster Preparedness and Response with Lessons from Hurricane Katrina
}

\author{
Deirdre T. Guion, Debra L. Scammon, and \\ Aberdeen Leila Borders
}

\begin{abstract}
The devastation of New Orleans as a result of Hurricane Katrina presents an opportunity and an obligation to examine the human and social factors that influenced the nation's response to this disaster. Lessons from Katrina suggest that a social marketing approach to disaster management could increase the likelihood of positive outcomes for individuals and communities when a disaster strikes. The authors propose an integrated approach to effective risk communications that encourages selfprotective behaviors.
\end{abstract}

$\mathbf{F}$ or centuries, catastrophic events were considered "acts of God" beyond the control of human decision makers. Today, there is widespread agreement that though natural disasters cannot be controlled, their impact can be managed. The traditional model of disaster management (Mileti 1999) recognizes that disasters evolve through time. Mitigation, preparedness, response, and recovery are identified as explicit phases that differ with regard to the management efforts that are required to deal with disasters. For 50 years, this model has served as the basis for disaster management practice and has guided research on experiences with disasters. Through the focused efforts of social science researchers, a wealth of information about disasters and their management has been amassed.

Despite the diversity of perspectives represented in the research, little of it has drawn from the field of marketing. What can marketing offer? Because of marketing's focus on the needs of consumers, we contend that a social marketing perspective could shift focus in disaster management from the needs of emergency management personnel to the needs of people whom they are charged with assisting. To put people's needs first, though, emergency managers need a deeper understanding of the perspectives of individuals in various subgroups of the population, particularly with regard to how they perceive and respond to risks.

Disasters are both sociological and political events, and though hurricanes and earthquakes are acts of nature, the disasters resulting from these events are social in origin

Deirdre T. Guion is Assistant Professor of Marketing, Haub School of Business, Saint Joseph's University (e-mail: dguion@sju.edu). Debra L. Scammon is Emma Eccles Jones Professor of Marketing, David Eccles School of Business, University of Utah (e-mail: mktdls@ business.utah.edu). Aberdeen Leila Borders is Assistant Professor of Marketing, University of New Orleans (e-mail: aborders@uno.edu). This article is dedicated to the memory of Derek F. Ridge and all the others who weathered the storm but did not survive its aftermath.

(C) 2007, American Marketing Association

(Tierney, Lindell, and Perry 2001). This study examines the human and sociological realities of area residents as they prepared for and responded to the events surrounding Hurricane Katrina. In this article, we apply a classic four-phase model of emergency management (Mileti 1999) to analyze the factors that affect people's preparedness for and response to disasters. Critical analysis of the human and organizational response to Katrina suggests that improved preparedness for and response to disasters requires behavior changes on the part of residents in the disaster area and emergency management organizations. To support such changes, we propose ways that the perspectives and tools of social marketing can encourage the needed behavior change and help improve disaster management. Our analysis demonstrates that communication is a key thread that runs throughout the phases of disaster. Thus, we propose an integrated approach to emergency management communication.

\section{Four-Phase Model of Disaster Management}

The four-phase model of disaster management (Mileti 1999) - mitigation, preparedness, response, and recoverydefines the basic language that planners, responders, and responsible authorities use when discussing and planning for the inevitable occurrence of disasters. Table 1 summarizes the key roles and participants involved in each phase of disaster management. We describe the focus and specific responsibilities of various entities, particularly governmental agencies and the media, throughout the phases of disaster. Although the model of disasters is linear, the phases can and do overlap. For the purposes of this study, the primary benefit of the four-phase model is its organizing framework.

\section{Mitigation}

Because natural hazards are only marginally subject to human control, the emphasis of disaster management during the mitigation phase is on preemptive measures that can 
Table 1. Major Participants in Emergency Management in Disaster Phases

\begin{tabular}{|c|c|c|c|c|}
\hline $\begin{array}{l}\text { Emergency Management } \\
\text { Phase/Participant }\end{array}$ & Mitigation & Preparedness & Response & Recovery \\
\hline $\begin{array}{l}\text { Government Agencies } \\
\text { •Federal } \\
\text {-State } \\
\text {-Local }\end{array}$ & $\begin{array}{l}\text { Planning } \\
\text { Organization } \\
\text { Coordination } \\
\text { Regulations } \\
\text { •Zoning } \\
\text { •Building codes } \\
\text { Infrastructure } \\
\text {-Levees } \\
\text {-Roads }\end{array}$ & $\begin{array}{l}\text { Organization } \\
\text { Infrastructure } \\
\text { Education }\end{array}$ & $\begin{array}{l}\text { Evacuation order } \\
\text { Evacuation support } \\
\text { Emergency aid } \\
\text { Search and rescue } \\
\text { Coordination of aid } \\
\quad \text { programs, such as } \\
\text { Medicare and } \\
\text { Medicaid }\end{array}$ & $\begin{array}{l}\text { Coordination } \\
\text { Shelter } \\
\text { •Short-term } \\
\text {-Long-term } \\
\text { •Rebuilding } \\
\text { Resources } \\
\text {-Tax incentives } \\
\text {-Loans } \\
\text {-Jobs and training }\end{array}$ \\
\hline $\begin{array}{l}\text { Media } \\
\text {-Television } \\
\text {-Radio } \\
\text { •Newspaper } \\
\text { • Other }\end{array}$ & $\begin{array}{l}\text { Agenda for public } \\
\text { debate }\end{array}$ & $\begin{array}{l}\text { Dissemination of } \\
\text { information } \\
\text {-Warnings } \\
\text {-Instructions for } \\
\text { response }\end{array}$ & $\begin{array}{l}\text { Vivid depiction of } \\
\quad \text { disasters and rescue } \\
\text { operations } \\
\text { Informal coordination } \\
\text { Hotlines }\end{array}$ & $\begin{array}{l}\text { Dissemination of } \\
\text { information about } \\
\text { accessing aid } \\
\text { Convey new image of } \\
\text { community }\end{array}$ \\
\hline $\begin{array}{l}\text { Nongovernmental } \\
\text { Organizations } \\
\text {-Relief organizations } \\
\text { •Community organizations } \\
\text { • Faith-based and religious } \\
\text { organizations }\end{array}$ & $\begin{array}{l}\text { Preassigned roles } \\
\text { (communications, } \\
\text { emergency shelter, } \\
\text { distribution of } \\
\text { supplies) }\end{array}$ & $\begin{array}{l}\text { Stockpile supplies } \\
\text { Expand warehouse } \\
\text { space } \\
\text { Pre-position } \\
\text { communications } \\
\text { equipment }\end{array}$ & $\begin{array}{l}\text { Provisions (food, } \\
\quad \text { medical supplies) } \\
\text { Shelter } \\
\text { Transportation } \\
\text { Support labor }\end{array}$ & $\begin{array}{l}\text { Provisions } \\
\text { Labor for renovation } \\
\text { and rebuilding }\end{array}$ \\
\hline
\end{tabular}

minimize the damage incurred as a result of a disaster. Mitigation involves long-range activities, initiated well in advance of a specific disaster or in response to a known risk. Federal, state, and local government agencies play a prominent role during this phase and, in general, are responsible for setting the agenda, engaging the appropriate players in planning, and establishing and enforcing rules and regulations to achieve agreed-on plans. Key responsibilities during mitigation include decisions about economic development - in particular, land-use policies; plans for infrastructure, such as roads and health care facilities; and identification of funding sources to support these community investments. Mass media can play a critical role during the mitigation phase because media coverage contributes to the formation of public attitudes, which in turn influence legislative actions (Levine 1982).

\section{Preparedness}

During the preparedness phase, emergency management focuses on reducing the negative consequences of disasters. Official concerns are disseminating messages aimed at encouraging people to make choices about protective behaviors and monitoring compliance with community plans. During this phase, governmental agencies are responsible for ensuring the safety of people in the disaster area and the environment. Community education is an important goal of preparedness, and thus the media are essential partners in this phase of disaster management. It is important that people understand their responsibility for being prepared and that they know what actions to take in advance of a disaster. Emergency managers have the responsibility to develop, disseminate, and provide necessary support for disaster plans, including evacuation and shelter.

\section{Response}

During the response phase, the need for comprehensive and integrated emergency management practices is greatest. During response, emergency management agencies undertake immediate, local efforts to provide short-term disaster relief, to facilitate the rescue of victims, and to provide shelter. The many organizations-including nongovernmental organizations (NGOs), such as the American Red Cross; local agencies with various specific responsibilities, such as police and fire departments, as well as search-and-rescue units; and agencies at the state and federal level, such as state emergency management agencies and the Federal Emergency Management Agency (FEMA)-move into action to meet the immediate needs in the affected communities. Coordination of these groups is a critical aspect of ensuring that needs are met as quickly and effectively as possible. Information is an important key to coordination, and the mass media play a major role in disseminating such information during this phase and the next.

\section{Recovery}

In the recovery phase, public organizations take on the task of restoring social systems and rebuilding physical environments. Damage assessment and rehabilitation are critical activities. As in the response phase, during recovery, the foremost issue is the political process involved in obtaining and distributing disaster aid. Processes for determining and monitoring eligibility for aid, for making people aware of sources of aid, and for the distribution of aid are implemented. Existing contracts for the delivery of specific types of assistance are executed, and supplemental vendors are identified if needs are not adequately met. An important role of the media during the recovery phase is communicating 
information about available assistance. The metrics and images used by the media to describe the needs in disaster zones can affect public attitudes and can help validate the need for aid. Because of their access to communications technology, the media may be called on to help disseminate information when official emergency personnel are unable to reach people in need.

As communities are recovering from a disaster, the cycle of nature continues, and sometimes recovery from one event can blend into the response to a subsequent event. The recurring cycle of disasters makes it critical that lessons learned during a disaster event are incorporated into the planning for and management of future disasters. Thus, the recovery phase is precisely the time when plans for mitigation should be laid. If this learning is not incorporated into the disaster management process, much of the value of the paradigm is lost.

\section{The Process of Emergency Management and Budget in Practice}

As Table 1 illustrates, several entities become involved at various stages of a disaster. These entities may have overlapping responsibilities and even competing agendas. The Office of Homeland Security, to which FEMA now reports, was established in October 2001 and was put into law with the Homeland Security Act of 2002 (Department of Homeland Security 2003) to help coordinate the work of various disaster response agencies in the wake of the September 11 terrorist attacks. An important aspect of this coordination is budget management and allocation of federal disaster aid. Not only does FEMA control allocation of federal aid resources, but it also has the power to determine the extent to which both NGOs and for-profit organizations are permitted to assist. The central place that FEMA holds in disaster recovery gives rise to the opportunity for fraud and corruption and creates barriers to the efficient functioning of the marketplace to allocate aid resources (Leeson and Sobel 2006).

The goal of comprehensive emergency management, and more recently the integrated emergency management system, is inclusive management practices that coordinate and integrate efforts across all levels of government (Fox News 2006; Perry 1985). In practice, however, these systems create inflexible, centralized bureaucracies that are predictably unable to respond to the very disasters they were designed to manage. The process of presidential disaster declarations illustrates this point. For a state to be eligible for federal emergency assistance, its governor must make a formal request for assistance. The president must then declare the area a disaster, which in turn triggers FEMA assistance. The actual dollar amount and allocation of FEMA funds is overseen by various congressional committees (Sobel and Leeson 2006). The subjective nature of FEMA disaster relief is substantiated with data that document that states that are politically important to a president's reelection bid historically have had a significantly higher rate of disaster declarations than less important states (Garrett and Sobel 2003), and states with representatives on the FEMA budget committees receive significantly more in disaster relief than states not represented on the committees (Garrett and Sobel 2003).

The aforementioned disaster management model focuses on the tasks of relief personnel and organizations. Experiences during Hurricane Katrina, which we detail subsequently, illustrate the potential insights that can be gained by shifting the perspective to that of the people in need.

\section{The Case of Katrina: An Exemplar for Lessons in Disaster Management}

\section{The Storm}

Hurricane Katrina is considered the costliest ( $\$ 81.2$ billion) Atlantic hurricane in U.S. history and, with more than 1800 fatalities, one of the deadliest (National Hurricane Center 2006). Over the course of 9 days (August 23-31, 2005), Katrina made landfall three times with strengths varying from Category 1 to Category 5, affecting the Bahamas, Cuba, Florida, Louisiana, Mississippi, and Alabama. Although the natural disaster of the hurricane caused damage to New Orleans, the human disaster contributed to the most extreme devastation, with $80 \%$ of the city flooded by the storm surge that breached three levees. The simultaneous occurrence of multiple disasters against a backdrop of socioeconomic disparity and political controversy exacerbated the damage and the chaotic response. The scope of the collision of natural and human-made disasters and the devastation captured through the lens of the media and viewed by millions are precisely what makes Hurricane Katrina an exemplar worthy of critical exploration and study.

\section{The Colorful Past of New Orleans}

Long before Hurricane Katrina ever made landfall, New Orleans was poised for disaster. The potential for flooding was ignored as funds targeted for infrastructure improvements were allocated to new projects rather than to maintenance of existing levees (Grunwald 2005). Topographically, approximately $55 \%$ of New Orleans lies eight feet below sea level and continues to sink three feet further below sea level every century (BusinessWeek 2000). Aggressive development at the state and federal levels further aggravated risks in this delicate topography. For example, the Mississippi River Gulf Outlet is a 76-mile shipping shortcut from the Gulf of Mexico to the Port of New Orleans designed by the Corps of Engineers (Grunwald 2005). Completed in 1965, the outlet has never reached its traffic potential but is a tremendous drain to the economy; critics contend that the Mississippi River Gulf Outlet costs $\$ 12,000$ per vessel per day and has destroyed more than 20,000 acres of needed adjacent wetlands (Grunwald 2005).

The unfortunate response to the topographical realities has been corruption at all levels of government. At first glance, the history of political corruption in Louisiana and New Orleans appears to take on epic proportions; three state emergency preparedness officials have been indicted for obstruction and mishandling of disaster relief funds in 2004, a former governor is serving a ten-year federal prison sentence for extortion, a former elections commissioner is serving time for a bribery sentence, and three former insurance commissioners have served time in prison (Applebome and 
Alford 2005). Further analysis reveals that though Louisiana has a colorful history of corruption, so, too, do other states with a high occurrence of natural disasters. Leeson and Sobel (2006) show that Louisiana, Mississippi, and Florida are the most politically corrupt states and are also the states hardest hit by natural disasters. Corruption notwithstanding, citizens of the United States, and specifically the residents of New Orleans, were failed by the very systems designed to assist them—systems funded using their tax dollars.

\section{Devastation Magnified by Economic and Ethnic Diversity}

At the time of the storm, $68 \%$ of the residents of New Orleans were African American, and approximately 23\% of the city's residents lived below the federal poverty level (Quinn 2006). With nearly a quarter of the population living in poverty, New Orleans's poverty rate was double the national average, but among its black population, the rate of poverty was $35 \%$ (Juan Williams 2006). The economy of New Orleans was concentrated in and dependent on revenue from the hotel, restaurant, and tourism service sectors, which accounted for $52 \%$ of the employment in New Orleans (Brookings Institution 2005).

When evacuation became necessary, the economic makeup of New Orleans complicated matters. Because a high percentage of residents in the city (approximately $20 \%$ ) did not have access to an automobile and because public transportation was not effectively used, a far greater number of residents than had been planned for were unable to leave the city. Although the New Orleans Superdome was designated as a "refuge of last resort" for residents with special needs (the disabled and the elderly), many other residents who were unable to leave the city ended up there. In addition, hundreds of others evacuated to the New Orleans convention center, apparently assuming that it was also being used as a shelter. At both locations, poor planning, evidenced by lack of management, no formal communications system, and inadequate subsistence supplies, quickly led to dangerous conditions. According to reports, city and state leaders and first responders did not know for three days that hundreds of residents sought refuge at the convention center (Brian Williams 2006).

\section{The Power of the Media}

The images that have come to define Hurricane Katrina were transmitted by mobile satellite into the homes of millions, who watched in horror as thousands of residents and tourists suffered in unimaginable conditions en route to and at the New Orleans Superdome. Because of the loss of basic means of communication by emergency managers, including land-based and cellular telephones, field reporters became conduits for information between evacuees and authorities (Brian Williams 2006). The media presence during Hurricane Katrina allowed the world not only to see the atrocities experienced by the evacuees but also to see clearly and repeatedly the contradictions and failings by all levels of government.

In addition to conveying images of the first-hand experience of Katrina, the media played an essential role in facilitating communication among disaster response personnel.
Local and state authorities monitored news coverage for information to assist in coordinating rescue efforts. One police officer, facing a fire at the gateway to the French Quarter, asked representatives from CNN to pass along to his colleagues, with whom he could not communicate, the message that fire had broken out and potentially threatened the Quarter (Eggerton 2005).

The emergence of the media as first responders highlights the power of the media in making meaning from the complexity of disasters to the public, both residents of the affected area and viewers. Although the media have been criticized for sensationalism in reporting, the vivid images conveyed to the world formed the basis of perceptions of the scope of the disaster and the magnitude of the consequences experienced throughout affected communities. As first responders, the media enabled the public to see images it otherwise would not have seen. People have also come to rely on the media to make sense immediately of a disaster and to reconcile contradictions. Watching a split-television screen was both revealing and baffling as President Bush patted then-FEMA director, Mike Brown, on the back, saying, "Brownie, you're doing a heckuva job" during a press conference, while other footage showed scores of desperate people outside the convention center begging for help (Lee 2006).

The intersection of disaster management activities and individual responses both during and after Hurricane Katrina reveals the unique vulnerabilities faced by New Orleans. One of the biggest hurricanes in recent history trapped a relatively immobile and resource-poor population within the confines of a city that was already on the brink of disaster as a result of previous economic development decisions and a weakened infrastructure. In the next section, we analyze people's experiences with disasters.

\section{Preparedness, Response, and Risk Communication}

If people are to be protected from the risks of disasters, it is critical that disaster managers understand how people assess disaster risks, what factors affect their perceptions of risk, and how they respond to risk communications. In this section, we draw heavily from research on risk to identify key factors that are likely to influence people's perceptions of and responses to the risks of disasters. Specifically, we focus on the phases of preparedness and response from the disaster management framework in our analysis.

\section{Preparedness}

Most people can rationalize the devastation from Hurricane Katrina as something that would never happen to them, but 91\% of Americans live in places that face a moderate to high risk of natural disasters or terrorism (Ripley 2006). Given this vulnerability to disasters, it is critical that communities and their individual residents become better prepared to deal with the risks of disasters.

Many current efforts to ensure public preparedness for disasters center on the provision of information about possible risks, but risk assessment is rarely an easy task because the actual risk depends on various factors. Risk is a function of the specific hazard (e.g., hurricane, earthquake, fire) as it 
interacts with the physical, social, and organizational environments of the specific community involved (Burnham 2006; McEntire et al. 2002).

Technology can provide warnings well in advance of a storm making landfall through the use of highly accurate strength and trajectory monitoring equipment. The National Oceanic and Atmospheric Association (NOAA) and the National Hurricane Center track and rate the progress and strength of storm winds using the Saffir-Simpson Hurricane Scale from Category 1 (winds of between 74 and 95 miles per hour) to Category 5 (winds of 156-plus miles per hour) (NOAA 2005). On the basis of these ratings, watches and warnings are issued when hurricane conditions are expected in a specific area within 36 and 24 hours, respectively. These watches and warnings are frequently accompanied by directives to consult radio, television, or NOAA Weather Radio All Hazards for bulletins of the storm's progress (NOAA 2006). Although these ratings indicate the wind strength of a storm, they provide only a relative sense of potential damage; lower-category storms may inflict greater damage than higher-category storms, depending on conditions when they make landfall. Furthermore, these warnings provide little direction as to what people should do to minimize the risk. People are left with the task of translating the technical information about wind strength into something that is meaningful and actionable.

Complicating the task of providing information about disaster risks is the fact that the risks from a specific natural disaster cannot be known with certainty. People's perceptions of the need to be prepared for disasters are likely to be affected by this uncertainty. Research suggests that people have difficulty understanding information about uncertain outcomes (Johnson, Payne, and Bettman 1988; Sprott, Hardesty, and Miyazaki 1998). In general, warnings about or predictions of an impending natural disaster are based on probabilities of occurrence, and actual risks are dependent on multiple aspects of the specific environment involved. This leads to a high level of uncertainty, and in the face of this uncertainty, general biases in the interpretation of information are likely to be exacerbated. Research suggests that people tend to underestimate some risks and overestimate others and that they have biased perceptions of the factors that contribute to these risks. Risk is particularly likely to be underestimated when people view themselves as invincible. Self-positivity biases (Taylor and Brown 1988) may lead people to believe that they are unlikely to experience harm from natural disasters; this bias has a direct impact on their efforts to be prepared for such disasters.

Various personal and social factors influence people's risk perceptions and, thus, their sense of urgency with regard to taking actions to be prepared for the risk (Drabek 1986; Tierney 1999). Income, education, and ethnicityparticularly as they are related to a person's ability to deal with potential losses from disasters - simultaneously influence risk perceptions and attendant behaviors. People with more stable incomes and better insurance coverage are better able to deal with the risks from disasters, leading to a lower perception of personal risk. Racial and ethnic minorities, people with low income, and those with little education tend to have higher perceptions of personal risk from natural hazards, in part because of their lack of resources and their vulnerable positions in society (Schmidlin 2006). The socioeconomic composition of New Orleans likely influenced both the actual and the perceived sense of risk as Katrina threatened to make landfall. As risk research suggests, perceptions of self-efficacy (Bandura 1986) influence both perceptions of risk and willingness to take self-protective behaviors. Next, we turn to people's responses in the face of disasters.

\section{Response}

Risk research is helpful in identifying some of the factors that are likely to affect people's responses to disaster risks (Rogers, Lamson, and Rousseau 2000). In the case of natural disasters, factors of particular relevance include people's previous experience with the specific type of disaster they are facing, the credibility of the sources of risk messages, the personal relevance of the risk, and their perceived ability to respond to the risks. With regard to previous experience, evidence from disaster research suggests that people with personal experience with a particular hazard tend to underestimate the likelihood of risk from future disasters because of two biases. First, some people with previous experience have a tendency to believe that "lightning does not strike twice" (Drabek 1986). Second, other people with previous experience feel less vulnerable because they survived a prior disaster; they feel more invincible because they lived through one disaster and have confidence that they can survive the next one (Schmidlin 2006). Despite evidence that people with experience may underestimate the chances of future disasters, research suggests that those who are experienced are more likely to take recommended action if a disaster occurs (Drabek 1986). However, this is likely to depend on experience not only with the disaster but also with the actions that were recommended during prior similar disasters.

For area residents living along the Gulf Coast, hurricanes are a fact of life. Over the past five years, numerous hurricanes have made landfall in this region. Many of these were preceded by voluntary evacuation orders that warned of the approaching storm and recommended that area residents leave the area. Not all these occurrences led to the expected damage and destruction, and those who evacuated experienced personal costs (travel expenses and the disruption of their personal and/or work lives) that, in retrospect, were unnecessary. Furthermore, those who chose not to evacuate did not face the forecasted danger. This anticlimactic experience can lull people into a false sense of security when the next storm approaches.

A common reaction to impending natural hazards is the denial of risks (Ripley 2006). The predicted consequences resulting from the magnitude of Hurricane Katrina were beyond the grasp of most people and far worse than the damage experienced from previous hurricanes in that region. Unable to process cognitively the eventuality of complete destruction and devastation likely from the storm, many people did not comply with recommended selfprotective actions, simply because most of the suggested measures for preparation appeared to be grossly inadequate.

Another factor likely to affect people's assessment of risk is the credibility of the source of risk-related messages. 
Responses to a disaster have been shown to be influenced by people's attitudes toward emergency managers. Drabek (1986) points out that, in part, as a result of generations of unpleasant life experiences with some authorities, ethnic minorities tend not to trust official disaster management personnel. In particular, law enforcement personnel are viewed with even less credibility (Perry and Lindell 1989).

Ethnic groups have been found to have preferences for different sources of information about disasters. Perry and Mushkatel (1984) find that blacks placed the highest confidence in the direct word of local authorities, whites found the mass media to be a credible source for warnings, and Mexican Americans had more confidence in warning information when it came from their network of family and friends. These ethnic differences in response to messages about disaster risks demonstrate how critical it is to understand source preferences and biases in communicating potential risks and appropriate response behaviors.

Beyond experience with emergency management personnel, racial differences in compliance with recommended protective behaviors have been shown to be related to differences in opportunity and the ability to take recommended actions. Poor people with limited disposable income have few choices about housing and transportation, which in turn limits their mobility, including their ability to stay or leave in the face of a disaster. For these reasons, people living in poverty may feel the impact of a natural disaster more strongly than those with higher incomes, who are more mobile and can evacuate. Generational residency patterns are also likely to affect response to risk. Some families have lived in the same neighborhood for generations and have few friends or family outside the immediate area. In case of a disaster, these people are not likely to have ready access to housing alternatives if they need to leave their homes.

Research also suggests that the perception of risk is related to how personally relevant the risk is. Risks are perceived as more personally relevant if the consequences are presented in concrete rather than abstract terms. Although there are some differences across ethnic groups in general, regardless of race, the more relevant the detail contained in a warning message, the more likely people are to heed it and comply with protective measures (Perry 1985).

As we noted previously, the effective communication of disaster risks is a challenging yet essential component of disaster management. Next, we examine the critical role of communication throughout the phases of disasters.

\section{Risk Communication}

Communication is a key thread that runs throughout the four phases of disaster framework; it is essential for the effective coordination of all the entities involved in disaster management (see Table 1). Effectively communicating to people about an impending disaster is critical because perception, response, and compliance are potentially life-and-death issues. It is essential that messages about disasters are consistent and that information about how to deal with risks is as precise and concise as possible. To deliver such messages, media can help ensure that communication is continuous and well coordinated across sources. How and when the media are engaged can dramatically influence perceptions of risk and response to emergency directives.
Mass media serve various functions for society, one of which is as a channel for emergency managers to disseminate information in times of imminent danger. Mass media have the reach and frequency to target many people who are otherwise inaccessible during a disaster (Schramm 1973). Although it can be argued that the media should be the most important vehicle for providing information about certain hazards and risks to people, there is no general agreement about how the mass media fit into the emergency management communication process. Compliance with warning messages is not automatic, regardless of the media used, but the nature of the channel that carries the warning has implications for the kinds of responses that people exhibit (Burkhart 1991).

As a communication tool, various media are used extensively during all phases of a disaster. The role of media during the preparedness and response stages of a disaster has been primarily to disseminate information to people in the onslaught of a disaster (Lindell and Perry 1991). Broadcast media communicate an array of information from weather conditions, to evacuation routes, to recovery efforts. It is important to note that most of what the media does in terms of relaying emergency information, warnings, and alerts is done voluntarily on both radio and television (McConnell 2004).

Both the amount and the type of information presented in the media can shape beliefs, attitudes, and perceived norms and can subsequently influence behavior (Fishman and Casarett 2006). Research shows that the social realities of heavy television viewers more closely resemble those depicted in the television world than that of light viewers. This was certainly the case immediately after Hurricane Katrina's devastation when, for hundreds of hours, broadcast after broadcast of negative images bombarded viewers. Hurricane Katrina underscored the essential role of the media in a time of crisis. Apart from fulfilling their traditional roles of information dissemination and making meaning of the disaster, a new role for media emerged during Katrina - that of first responders. At every stage during and after the disaster, the media were integrally involved.

The myriad factors affecting people's perceptions of and responses to risk make effective communication of risks challenging at best. To meet these challenges, emergency managers could benefit from taking the perspective of residents in the disaster area. Social marketing offers just such a perspective.

\section{A Social Marketing Perspective on Facilitation}

\section{Preparedness and Response to Disasters}

A key goal in disaster management is the protection of people and the enhancement of their quality of life while remaining prepared for the ongoing possibility and aftermath of disasters. The preceding analysis of Hurricane Katrina and of people's experiences during disasters suggests that to achieve effective preparedness, behavioral changes on the part of both residents in the disaster area and emergency managers are essential. In this regard, social marketing has great potential for improving preparedness and 
response by focusing attention on the needs of disaster victims. As Andreasen (2002, p. 7) notes, a social marketing perspective is unique because it "(1) holds behavior change as its bottom line,... (2) is fanatically customer-driven,... and (3) emphasizes creating attractive exchanges that encourage behavior." Through culturally sensitive market research, careful market segmentation and targeting, and scrupulous pretesting of marketing programs, social marketing has the potential to address the individual differences identified in our analysis that affect people's perceptions of disaster risks and their responses to risk. Such an approach could be used to ensure that communications about preparedness that precede a disaster and communications about response during a disaster are designed with the audience in mind rather than with the needs of authorities and emergency managers as their focus.

Andreasen $(1995,2002)$ suggests that behavior change can be conceptualized as a process. By breaking the process down into stages, the factors that affect the adoption of a recommended behavior at each stage can be more easily identified and addressed directly. Market segmentation is an important concept in social marketing. It is important to recognize that not all members of a target population will be in the same stage of adoption of a recommended behavior or will perceive the costs and benefits of the recommended behavior in the same way. This implies that different approaches to behavior change may be necessary for different segments of the population.

The stages in the behavior change process that Andreasen (2002) describes broadly parallel the phases of disaster management. In social marketing terms, preparedness can be viewed as including the stages of precontemplation, when the audience is first beginning to consider a recommended behavior, and contemplation, when they are evaluating the potential efficacy of the behavior and its value to them. The response phase is analogous to social marketing's action stage, when the audience has made a commitment to and is engaging in the behavior. The recovery and mitigation stages depend on what social marketing refers to as maintenance, which is when the recommended behavior has been adopted and now must be continued.

A social marketing approach to disaster preparedness should be based on an understanding of the factors that act as barriers to people taking recommended self-protective actions. During precontemplation, overcoming tendencies by the target audience to ignore or screen out disaster messages selectively is a key task. Our analysis suggests that perception of risk is related to various individual characteristics, including race, socioeconomic status, experience with prior disasters, personal relevance of the risk, and perceived self-efficacy. An understanding of how different subgroups within the population view the risks will give disaster managers a stronger basis for developing risk communication strategies that can overcome selective perception by various groups.

Social marketing suggests that at the contemplation stage, factors that are important to the consideration of a recommended behavior include the audience's perception of benefits and costs of the behavior, social influences that surround the adoption of the behavior, and the perception of control over behaviors related to the recommended actions. Our analysis suggests that people evaluate the costs and benefits of self-protective actions within the social context in which they live. As people experience a disaster, they interact with family, neighbors, and friends for help in interpreting and making meaning of the disaster (Drabek 1986) and in determining how they will respond. An understanding of the perceptions of the target audience on each of these dimensions provides the basis for developing strategies designed deliberately to increase perceived benefits and decrease perceived costs, to enhance people's abilities to perform the recommended behavior, and to capitalize on existing social networks to support the desired behavior. Strategies focused on these elements that are essential to behavior change should lead to improved compliance with recommended actions. Finally, a social marketing perspective acknowledges that continuation or maintenance of the recommended behavior depends on rewards for adoption and reminders of what behavior is recommended. In the context of disaster preparedness, this implies that strategies should be implemented to reward people who have adopted the desired behavior (or to penalize those who have not) and to remind them not only of the need to be prepared but also how to become prepared.

Strategies applying a social marketing perspective can incorporate several components to help achieve the desired results. Rothschild (1999) suggests that three components can be particularly helpful. Specifically, he identifies (1) education, (2) laws and regulations, and (3) marketing as tools for behavior change. Historically, many public policies aimed at increasing consumer engagement in actions deemed to be beneficial to them (e.g., quitting smoking) and/or to society at large (e.g., obeying traffic safety regulations) have been grounded in the assumption that knowledge is an essential precursor to action. Thus, many campaigns include a large education component, focusing on information about the reasons the audience should adopt the recommended behavior and the ways people can engage in the behavior.

However, having the knowledge of what to do and how to do it sometimes may not be enough to motivate appropriate action, and additional tools may be required to support behavior change. Rothschild (1999) further contends that government action-specifically, laws and regulationsmay help when people cannot be trusted to take appropriate actions. Ripley (2006) points to some familiar examples, including mandatory car insurance, seat-belt laws, and smoking bans. However, it is important to recognize that restrictions on behavior may have some unintended consequences. Seat-belt laws impose penalties for nonuse of the restraining devices, leaving little discretion to the motorist. Seat-belt usage has increased in the context of such laws, but the cost of monitoring compliance is high.

The third tool that Rothschild (1999) suggests can be helpful is marketing. He conceptualizes marketing as a means to affect the perceived costs and benefits of the desired behavior. In the context of disaster preparedness, for example, marketing tools could help reduce the perceived cost to people of preparing for a disaster by ensuring that preparedness supplies are readily available and easily accessible. Advertising, public relations, and other promotional 
tools could be used to disseminate information and to motivate behavior.

Rothschild (1999) notes that social marketing campaigns should strike a balance among the three components of education, laws and regulation, and marketing to accomplish behavior change while not relying exclusively on any one element. In the next subsections, we analyze two situations in which the behavior of the people affected is critical to improved outcomes from disasters. We examine a current disaster preparedness campaign and the issuance of an evacuation order and suggest ways that both could be improved through taking a social marketing approach.

\section{Campaign for Encouraging Disaster Preparedness}

From the government's point of view, individual preparedness includes at least three things:

1. Immediate access to resources such as food, water, medications, radio, and other necessities for evacuation and living in sheltering conditions;

2. Formation of family plans, including meeting points, phone numbers, and other preestablished decisions to be used to reconnect with one another; and

3. Knowledge of local and regional evacuation routes and shelter locations (Redlener and Berman 2006).

According to a survey by the National Center for Disaster Preparedness at Columbia University in October 2005, only $53 \%$ of respondents described themselves as prepared (Ripley 2006). With regard to the specific components of preparedness, the findings were even more concerning. Only $43 \%$ of respondents reported having a family emergency preparedness plan, only $31 \%$ reported having all the major elements that are part of a preparedness "kit," and only $34 \%$ reported being familiar with emergency or evacuation plans in their community (Ripley 2006). It appears that people may not be well informed or motivated to be prepared for disasters, despite the recent and dramatic experiences with Hurricane Katrina. An analysis of the government program to encourage disaster preparedness reveals some gaps in which a social marketing initiative could help.

Much of the current federal effort to increase residents' preparedness for disasters focuses on promoting "Ready.gov" and similar Web sites that contain information about preparedness. This program is primarily informational, focusing on letting people know where they can find information about preparedness for disasters. Recently, this initiative has adopted an "all-hazard-preparedness" message intended to convey information about preparedness for events from terrorist attacks, to natural disasters, to power outages (Redlener and Berman 2006). Our analysis suggests that benefits of preparedness are likely to be perceived as greater when the risks are portrayed as more personally relevant. Generalizing disaster preparedness to the level of allhazard preparedness may actually reduce the personal relevance of disaster. Although the notion of all-hazard preparedness may provide an umbrella for various disasters, thus expanding relevance to people who face different types of disasters, the message may lose its impact because of a lack of specificity and personalization. A social marketing approach would recognize the importance of increasing the perceived benefits of preparedness to subgroups in the population and of carefully pretesting messages to determine how various target groups perceived the benefits.

A social marketing approach would also examine the costs of the desired behavior from the people's point of view; for example, one of the costs associated with being prepared involves learning about disaster preparedness kits and evacuation guidelines. Although information is readily available on the Ready.gov Web site, this strategy relies on people's efforts to locate the Web site and search for the information they need. Although the Internet can be an important resource for providing information relevant to disaster preparedness and response, it shifts much of the burden for being informed to the people, some of whom may not have access to the Internet. Other means for disseminating preparedness information must be considered.

To ensure that the message about preparedness is widely accessible, information could be bundled together with relevant, regular communications. For example, reminders about specific financial documents that should be taken if evacuation is necessary could be included in bank statements, and reminders about useful medical information, such as prescriptions taken, and how to cope with chronic diseases or disabilities during evacuation and in shelter conditions could be encouraged by health care providers. Such strategies would have the added benefit of enlisting credible significant others (e.g., physicians) as partners in the efforts for preparedness.

Opportunities should also be sought to engage for-profit firms and organizations in preparedness efforts. For example, companies such as the Home Depot and Wal-Mart demonstrated their ability to deploy inventory in advance of Hurricane Katrina. Because people shop at retailers such as these to obtain supplies, the retailers can be essential partners in both conveying messages about preparedness and providing access to preparedness kits and preparedness supplies.

Successful marketing communications campaigns emphasize the importance of frequency in creating knowledge. Thus, attention should be paid to programmatic dissemination of messages and the identification of opportunities for reminders. The all-hazard-preparedness message is being promoted through Homeland Security and has been adopted by state and local agencies and is supported through press releases, advertising, Web sites, and infomercials. It has also been coordinated with the National Preparedness Month campaign that the American Red Cross has instituted. The latter creates an opportunity to saturate people with recurrent messages over a short period, thus increasing the likelihood that they will be exposed to and retain the message. The joint campaign involves multiple sources, thus expanding the reach and credibility of the message.

\section{Increasing Compliance with an Evacuation Order}

If the public is to be protected from the dangers of a disaster, evacuation may be inevitable. Whether evacuation is voluntary or mandatory, communication of both the risks that can be avoided through evacuation and the recommendations for smooth and timely evacuation is essential. For 
messages about evacuation to be effective, our analysis suggests that it is important to include information about the risks that people may encounter, the likelihood and severity of the risks, the specific consequences of those risks, and the means by which the risks can be avoided or diminished.

The communications challenges of an evacuation order begin with decisions about who will issue the order. In the case of Katrina, a voluntary evacuation order was issued on Friday, August 26, 2005, by Governor Blanco and Mayor Nagin. By Saturday, August 27, 2005, the predictions for damage from the storm prompted a mandatory evacuation order-the first ever mandatory order in the history of New Orleans-signaling the forecasted intensity of the damage, destruction, and human suffering from Hurricane Katrina. The confusion surrounding the issuance of this order foreshadowed the chaos that was to follow. Because the hurricane was forecast to hit New Orleans and a large surrounding region, both the mayor of New Orleans and the governor of Louisiana were alerted by Max Mayfield, head of the National Hurricane Center, that a mandatory evacuation was recommended.

Mayfield's involvement in the evacuation order demonstrated three important principles of effective risk communication. First, he had become somewhat of an "expert celebrity" through his ability to use high-resolution graphics, Doppler radar, and "point-and-click" methods to pinpoint storm-tracking accuracy and to interrupt programming across broadcast and cable systems nationwide. Second, his involvement, along with that of other authoritative sources, such as the Weather Channel, a dedicated cable weather station that labeled itself "the hurricane authority," added to the credibility of the message that the storm was highly likely to inflict substantial damage and destruction. Third, Mayfield's warnings were specific about the likely consequences of the storm:

Most of the area will be uninhabitable for weeks,... perhaps longer. At least one-half of well-constructed homes will have roof and wall failure. Gabled roofs will fail,... leaving those homes severely damaged or destroyed. Airborne debris will be widespread ... and may include heavy items such as household appliances and even light vehicles.... Power outages will last for weeks....Water shortages will make human suffering incredible by modern standards.... Trees will be snapped or uprooted.... Few crops will remain.... Livestock left exposed to the winds will be killed. (NOAA 2006)

The gravity of this evacuation order presented the risks in such a way that residents would recognize the benefits of complying with that evacuation order.

However, missing in the evacuation communications was sensitivity to the costs that many residents would incur if they evacuated, costs that would be too great for some to bear. In a recent study of Gulf Coast evacuees, Blendon and colleagues (2006) reported that respondents believed that evacuation would be dangerous; roads would be too crowded; and shelters would be unsanitary and would not have adequate food, water, and medical supplies. Respondents were also concerned about the security of their homes and belongings left behind (Blendon et al. 2006). These concerns were likely fueled by the vivid media images from Katrina, showing freeway congestion, looting in neighbor- hoods, and stranded residents. All these concerns represent barriers to action, and emergency managers should consider ways that these barriers can be overcome.

Perceived self-efficacy with regard to the ability to evacuate also appears to have been a problem for some people. Blendon and colleagues (2006) report that many of those who did not evacuate either were in poor health themselves or stayed behind to care for someone who was physically unable to leave. These findings underscore just how vulnerable some segments of the population are and the importance of ensuring that they are aware of resources available to assist them.

Blendon and colleagues' (2006) study highlights the importance of taking the perspective of residents of the effected communities when designing effective risk communications. Unless risk communications are designed with an understanding of the biases and concerns of these residents, the messages are not likely to motivate the desired behavior.

The Katrina evacuation also illustrates the importance of including appropriate information in messages. Messages should speak to the audience in terms that are relevant to them. If people are to evacuate, they must have places to go. For most people, this means a place other than an emergency shelter. Blendon and colleagues (2006) report that a majority of respondents would prefer to find shelter with family and friends. Despite this preference, many New Orleans residents did not have an out-of-town evacuation destination. The Katrina evacuation messages did not consistently include specific information about evacuation shelters, evacuation routes, or evacuation transportation. The message that the New Orleans Superdome was the "shelter of last resort" was well disseminated but did not clearly articulate for whom that shelter was intended. Although the message regarding the inability of public transportation to assist with evacuation was well publicized, numerous Amtrak trains with hundreds of empty seats left the city unannounced (Leeson and Sobel 2006).

Beyond the content of risk messages, several other aspects of effective communications are worth considering. A particular challenge during disasters is that emergency responders have different physical communication systems that operate on different frequencies using different equipment. Interoperability of equipment and systems should be the goal in a disaster. Beyond equipment standards, however, there is also a need for multiple means of communication. When there is an impending disaster, more than one fail-safe technological solution should be operational. An important lesson from Katrina is that disaster managers should not rely solely on a single broadcast system in a disaster area.

Redundancy in communications vehicles is also important in terms of the ability of different segments of the population to access information. Minority, lower-income, and elderly populations, often the hardest hit by natural disasters, may make up a greater percentage of the audience without cable or digital communications capabilities. Thus, although advanced communication technology may offer advantages, basic technology that is more widely available among the population is also essential to effective communication. 
Beyond consideration of the design and dissemination of effective risk communications to stimulate desired protective actions on the part of residents in the threatened area, emergency managers must also consider how to effectively address the events that unfold during a disaster. These challenges are public relations issues that involve credibility, reliability, and resultant perceptions. An example from NASA's response to two space disasters highlights alternative approaches to disaster management.

On January 28, 1986, the space shuttle Challenger exploded before a worldwide television audience $73 \mathrm{sec}-$ onds after liftoff. NASA's public relations handling of the tragedy was an unmitigated disaster. NASA's mission control commentator called the explosion a "major malfunction." Five hours passed before the first news conference. All documents pertaining to the disaster were destroyed, leaving reporters to speculate, seek information elsewhere, and concoct their own stories (Seitel 2004). NASA also waited until nightfall to attempt to remove debris from the space shuttle and used decoy ambulances to divert media attention. The result was a two-and-a-half-year suspension of the shuttle program.

Seventeen years later, on Saturday, February 1, 2003, NASA showed the world the public relations lessons it had learned. When the space shuttle Columbia broke into several pieces on reentry over Dallas, Tex., within two hours, NASA administrators held a news briefing to underscore the gravity of the situation and to express the agency's profound sorrow for "a tragic day for the NASA family." The two administrators then meticulously traced the events of the day, including communication with astronauts' families, President Bush, and other federal officials. A few hours later, a press conference was held by President Bush confirming NASA's report (Seitel 2004).

Similar issues were faced by all levels of government in the aftermath of Katrina. The lessons learned from NASA include the benefits of a timely and credible response, acknowledgment of the magnitude and scope of the devastation, and close communication with relevant parties. People are not as concerned with whether all the information is known but rather that what is known is honestly communicated as quickly as possible.

Beyond these aspects of effective risk communication, it is important to consider the central role of mass media, and particularly television, in Katrina. Not only did television affect the world through its combination of visual and audio that stimulated people's senses in lasting and memorable ways, but it also helped people reconstruct and make meaning of the reality of the event. Broadcasters became first responders, providing vital news and information to everyone, including police and firefighters (Eggerton 2005). Some of the negative consequences experienced by New Orleans residents were lessened by the media's communications, relief, and response efforts. This new functionality of the media served to provide an increased impetus on coordination and cooperation as all eyes were focused on the events as they unfolded. The unique perspective given by the media was that of the residents of the effected areas. We suggest that the perspectives of residents in the disaster area are central for communities and organizations as they prepare for and respond to disasters.

\section{A Social Marketing Approach for Communities and Organizations}

The goal of protecting people during disasters can be addressed at several levels. Ultimately, the impact of a disaster is related to the actions taken by individuals. As we illustrated previously, an essential component of a successful disaster management plan is the encouragement and support of self-protective behaviors by disaster-area residents. However, it is also important to recognize that preparedness can be addressed at other levels as well. Because the likelihood of disasters and their impact are situation specific, communities are frequently the focus of disaster management efforts. At the broadest level, preparedness can be addressed by government agencies and disaster managers through changes in the structural environment. For example, creation of the Department of Homeland Security to which FEMA reports is a structural intervention. Efforts to enhance preparedness and response at these various levels are not independent. As individuals act, their collective behavior affects the ultimate effectiveness of community response. As communities respond, their actions affect and are affected by structural responses. A social marketing perspective would enable communities and organizations to be more responsive to their constituencies. Agencies such as FEMA and local emergency responders typically are more product than customer oriented. By considering how best to meet people's needs and make resources more accessible, agencies could identify creative means for changing the perceived costs and benefits of recommended actions.

\section{Discussion and Conclusions}

Our analysis began with a brief review of the four-phase model of disaster management currently used at all levels of the U.S. government. For 50 years, this model has guided research on experiences with disasters and disaster management practices. Through the focused efforts of social science researchers, a wealth of information about disasters and their management has been amassed. Despite the diversity of perspectives represented in the research, little of it has drawn from the field of marketing. Social marketing offers numerous insights that can improve disaster management.

Scholars in the field of disaster research suggest that disaster management can be improved by refining the type and level of analysis of disasters, shifting the focus away from hazards over which humans have little control to vulnerabilities that humans can manage. With a similar change in perspective, social marketing would shift focus in disaster management from the needs of emergency management personnel (the dissemination of information about the technical characteristics of a threatening storm and about evacuation orders) to the needs of the people whom they are charged with assisting (information that reduces uncertainty, that provides explanations, and that identifies resources for assistance). To put people's needs first, emergency managers need a deeper understanding of the perspectives of individuals in various subgroups of the population, particularly with regard to how they perceive and respond to risks.

This study identified various heuristics and biases that lead people to discount threats. It also identified several fac- 
tors that influence people's perceptions of the costs and benefits of taking action to avoid or minimize threats. Taking these factors into consideration, emergency managers should focus on reducing perceived costs and increasing perceived benefits to residents from taking recommended self-protective measures. It is understandable that residents whose homes are all they know and whose personal possessions are all they have would be hesitant to leave home when ordered to evacuate. The costs of evacuating include leaving behind these most valued possessions and entrusting them to the care of authorities whom they do not trust. They also include the psychological stress of dealing with the now-vivid images of chaos in shelters, gridlock on highways, and unavailability of public transportation to facilitate evacuation. Realizing how high these perceived costs are, emergency managers must work to ensure that the perceived benefits of evacuation and other self-protective behaviors are increased.

We suggest several fruitful avenues for future research that could help optimize the success of social marketing campaigns aimed at encouraging residents to take recommended self-protective behaviors. Risk and consumer behavior research is equivocal with regard to how prior experience influences people's assessments of risk and the likelihood of taking protective actions in the face of risk. The aftermath of Katrina presents the opportunity to explore further the effects of experience gained in responding to risk. The scope and magnitude of the damage and destruction experienced during Hurricane Katrina was unthinkable to most residents of the affected areas. The self-protective behaviors that were recommended were totally inadequate in the circumstances. Exploration of how these circumstances affected people's confidence and trust in emergency management personnel and how they affected people's sense of self-efficacy for dealing with the disaster would be valuable. Does experience with a disaster on the scale of Katrina increase or decrease the likelihood of complying with recommendations in a future disaster? Because of the prominence of the images from Katrina portrayed by the media to the world outside New Orleans, there is also an opportunity to explore how experience gained vicariously by nonresidents watching the vivid images differs from that of residents who actually lived through the devastation and destruction, many of whom lost everything they had. Knowledge of how firsthand and vicarious experience differentially affect people's likelihood of engaging in recommended self-protective behaviors could be valuable in designing disaster communications for different audiences.

New Orleans was embroiled in political and economic turmoil before Katrina. In that context, the population clearly did not trust the disaster authorities, which contributed to a lack of compliance with recommended actions. Emergency response was further hampered because of a lack of coordination among disaster agencies, and at times there was actual opposition by responsible authorities to the participation of NGOs, such as the American Red Cross, and private entities, such as Wal-Mart, in response efforts. In handling disasters on the scale of Katrina, it is simply not possible for a single entity to provide the needed response. It is critical that disaster management practices facilitate the involvement of NGOs and for-profit companies and organi- zations in disaster preparedness and response efforts. Partnerships between these organizations and FEMA have the potential to enhance the welfare of people dealing with disasters. Their involvement could both enhance the resources available and provide a much-needed source of confidence and trust.

Our analysis also raised questions about the practicality and effectiveness of a centralized disaster management authority in coordinating response to disasters. Although centralized, comprehensive communication is critical, centralized management is a proven failure. With centralized communication comes the opportunity to have one person associated with disseminating all disaster messages.

Our analysis also suggests the need for critical assessments of the appropriateness of the emergent role of the media as first responders in disasters. Analysis of whether the media are well suited for this role and the consequences of them adopting this role is necessary. Despite the positive impacts of the media during Katrina, it is important to question whether having the media operate as first responders enabled those entrusted with true authority to shirk their responsibilities. Such unintended consequences must be avoided in the future. The most effective role of the media is that of a partner in communications rather than that of primary managers and first responders, roles that were foisted on them in the chaotic aftermath of Katrina.

Finally, our analysis compels us to address national issues that, before Katrina, many treated as resolved. Disparities related to race, income, and education; lack of civic engagement; and local, state, and federal government corruption all contributed to the experiences of this disaster. These same issues could emerge if a disaster were to strike one of many U.S. metropolitan areas. New Orleans is not a unique case; the constellation of factors that contributed to the human disaster there could surface anywhere in the United States.

The number and magnitude of disasters in this country and internationally is expected to increase. Professionals and academics in marketing and public policy have the opportunity and responsibility to analyze and learn from the disaster known as Hurricane Katrina and to use this knowledge to benefit the greater good.

\section{References}

Andreasen, Alan R. (1995), Marketing Social Change. San Francisco: Jossey-Bass.

(2002), "Marketing Social Marketing in the Social Change Marketplace," Journal of Public Policy \& Marketing, 21 (Spring), 3-13.

Applebome, Peter and Jeremy Alford (2005), "History of Corruption in Louisiana Stirs Fears That Aid Will Go Astray," New York Times, (October 1), A10.

Bandura, Albert (1986), Social Foundations of Thought and Action: A Social Cognitive Theory. Englewood Cliffs, NJ: Prentice Hall.

Blendon, Robert J., John M. Benson, Tami Buhr, Kathleen J. Weldon, and Melissa J. Herrmann (2006), "High-Risk Area Hurricane Survey," Harvard School of Public Health Project on the Public and Biological Security, (July 5-11), (accessed August 
14, 2006), [available at http://www.hsph.harvard.edu/hurricane/ topline.doc].

Brookings Institution (2005), "New Orleans After the Storm: Lessons from the Past, a Plan for the Future," Brookings Institution Metropolitan Policy Program, (October).

Burkhart, Ford N. (1991), Media, Emergency Warnings, and Citizen Response. Boulder, CO: Westview Press.

Burnham, Gilbert (2006), "Preventing Disaster: Realizing Vulnerabilities and Looking Forward," Harvard International Review, 28 (1), 83-84.

BusinessWeek (2000), "Come 2100, New Orleans Could Be an Underwater Attraction," (February 1), (accessed September 4, 2006), [available at http://www.businessweek.com/bwdaily/ dnflash/feb2000/nf00201f.htm?scriptFramed?scriptFramed].

Department of Homeland Security (2003), "Executive Order (EO13284): Amendment of Executive Orders and Other Actions in Connection with the Establishment of the Office of Homeland Security," (January 27), (accessed December 2, 2006), [available at http://www.dhs.gov/news/releases/press_release_0072. shtm].

Drabek, Thomas E. (1986), Human System Responses to Disasters: An Inventory of Findings. New York: Springer-Verlag.

Eggerton, John (2005), “A Failure to Communicate," Broadcasting \& Cable, 135 (37), 8.

Fishman, Jessica and David Casarett (2006), "Mass Media and Medicine: When the Most Trusted Media Mislead," Mayo Clinic Proceedings, 81 (3), (accessed August 23, 2006), [available at http://www.mayoclinicproceedings.com].

Fox News (2006), "Fox Facts: FEMA and Federal Disaster Assistance," (accessed April 27, 2006), [available at http://www. foxnews.com/0,3566,193380,00.html].

Garrett, Thomas and Russell S. Sobel (2003), "The Political Economy of FEMA Disaster Payments," Economic Inquiry, 41 (3), 496-509.

Grunwald, Michael (2005), "Canal May Have Worsened City's Flooding," Washington Post, (September 14), A21.

Johnson, Eric J., John W. Payne, and James R. Bettman (1988), "Information Displays and Preference Reversals," Organizational Behavior and Human Decision Processes, 42 (August), $1-24$.

Lee, Spike (2006), When the Levees Broke: A Requiem in Four Parts, HBO documentary, (August 21).

Leeson, Peter T. and Russell S. Sobel (2006), "Weathering Corruption," working paper, Department of Economics, West Virginia University, and Mercatus Center, George Mason University.

Levine, Adeline G. (1982), Love Canal: Science, Policy and People. Lexington, MA: D.C. Heath.

Lindell, Michael K. and Ronald W. Perry (1991), Behavioral Foundations of Emergency Planning. New York: Hemisphere Books.

McConnell, Bill (2004), "This Is Not a Test," Broadcasting \& Cable, (August 16), 1.

McEntire, David A., Christopher Fuller, Chad W. Johnston, and Richard Weber (2002), "A Comparison of Disaster Paradigms: The Search for a Holistic Policy Guide," Public Administration Review, 62 (3), 267-81.
Mileti, Dennis (1999), Disasters by Design: A Reassessment of Natural Hazards in the United States. Washington, DC: Joseph Henry Press.

National Hurricane Center (2006), "Hurricane Basics," (accessed April 20, 2006), [available at http://www.nhc.noaa.gov/ HAW2/].

NOAA (2005), "NOAA's National Weather Service Celebrates 135th Anniversary," (February 9), (accessed April 9, 2006), [available at http://www.nws.noaa.gov/pa/history/135 anniversary].

(2006), "NOAA Bulletin," (accessed August 15, 2006), [available at http://www.srh.noaa.gov/data/warn_archive/LIX/ NPW/0828_214001.txt].

Perry, Ronald W. (1985), Comprehensive Emergency Management: Evacuating Threatened Populations. Greenwich, CT: JAI Press.

— and Michael K. Lindell (1989), "Communicating Threat Information for Volcano Hazards," in Bad Tidings: Communication and Catastrophe, L.M. Walters, L. Wilkins, and T. Walters, eds. Hillsdale, NJ: Lawrence Erlbaum Associates, 47-62.

- and Alvin Mushkatel (1984), Disaster Management: Warning and Community Relocation. Westport, CT: Quorum Books.

Quinn, Sandra Crouse (2006), "Hurricane Katrina: A Social and Public Health Disaster," American Journal of Public Health, 96 (2), 204.

Redlener, Irwin and David A. Berman (2006), "National Preparedness Planning: The Historical Context and Current State of the U.S. Public's Readiness, 1940-2005," Journal of International Affairs, 59 (2), 87-103.

Ripley, Amanda (2006), "Floods, Tornadoes, Hurricanes, Wildfires, Earthquakes.... Why We Don't Prepare," Time, 168 (9), 54.

Rogers, Wendy A., Nina Lamson, and Gabriel K. Rousseau (2000), "Warning Research: An Integrative Perspective," Human Factors, 42 (1), 102-139.

Rothschild, Michael L. (1999), "Carrots, Sticks, and Promises: A Conceptual Framework for the Management of Public Health and Social Issue Behaviors," Journal of Marketing, 63 (October), 24-37.

Schmidlin, Thomas W. (2006), "On Evacuation and Deaths from Hurricane Katrina," Bulletin of the American Meteorological Society, 87 (6), 754-56.

Schramm, William (1973), Men, Messages, and Media: A Look at Human Communication. New York: Harper \& Row.

Seitel, Fraser P. (2004), The Practice of Public Relations, 10th ed. Upper Saddle River, NJ: Pearson/Prentice Hall.

Sobel, Russell S. and Peter T. Leeson (2006), "Government's Response to Hurricane Katrina: A Public Choice Analysis," Public Choice, 127 (1-2), 55-73.

Sprott, David E., David M. Hardesty, and Anthony D. Miyazaki (1998), "Disclosure of Odds Information: An Experimental Investigation of Odds Format and Numeric Complexity," Journal of Public Policy \& Marketing, 17 (Spring), 11-23.

Taylor, Shelly E. and Johnathon D. Brown (1988), "Illusion and Well-Being: A Social Psychological Perspective on Mental Health," Psychological Bulletin, 103 (2), 193-210.

Tierney, Kathleen J. (1999), "Toward a Critical Sociology of Risk," Sociological Forum, 14 (2), 215-42. 
_ Michael K. Lindell, and Ronald W. Perry (2001), Facing the Unexpected: Disaster Preparedness and Response in the United States. Washington, DC: Joseph Henry Press.

Williams, Brian (2006), "We Were Witnesses," NBC Nightly News transcript, (accessed August 29, 2006), [available at http://www. msnbc.msn.com/id/14518359/page/4/print/1/displaymode/ 1098].

Williams, Juan (2006), "Getting Past Katrina," (accessed September 1, 2006), [available at http://www.nytimes.com/2006/09/01/ opinion/01williams]. 
Copyright of Journal of Public Policy \& Marketing is the property of American Marketing Association and its content may not be copied or emailed to multiple sites or posted to a listserv without the copyright holder's express written permission. However, users may print, download, or email articles for individual use. 